\title{
In memoriam Prof. Georg Kretschmer
}

\section{October 1941 to 10 April 2013}

\author{
Thomas Hölzenbein
}

Published online: 2 December 2014

(C) Springer-Verlag Wien 2014

Georg Kretschmer was born in Vienna. After Medical School at the University of Vienna, he started his career at the Department of Pathology of the Vienna General Hospital. In 1968, he switched to general surgical training at the I. Department of Surgery. From 1976 to 1977, he was granted a Max Kade scholarship and studied pancreatic transplantation at the University of Minnesota under the leadership of Prof. J. S. Najarian. In 1980, he was awarded his $\mathrm{PhD}$ and became Professor of Surgery in 1986. From this time on, his main professional interest was on vascular surgery with emphasis on peripheral vascular surgery and organ transplantation. He was President of the Austrian Society of Vascular Surgery, the Austrian Society of Angiology, and the European Society of Vascular Surgery. His vascular surgery publications encompass nearly all fields of open and endovascular arterial interventions and reconstructions of great veins. His contributions to modification of anticoagulation to improve bypass patency and patient survival have a lasting impact on the way vascular surgery patients are managed today. He published over 171 original articles, 5 reviews, and 47 book chapters. He was co-author of Breitner's surgi-

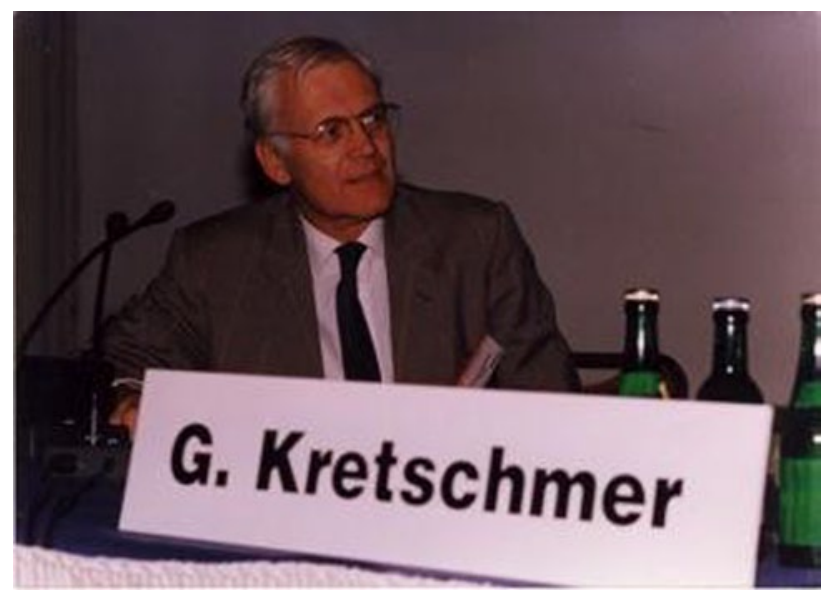

Prof. Georg Kretschmer (Foto: privat)

cal textbook and editorial board member of several German and English speaking journals. He is survived by his daughter and two sons, four grandchildren and his wife Sieglinde Kretschmer MD. 